\title{
Kapasitas Infrastruktur dan Fasilitas pada Kereta Api Angkutan Barang dan Logistik
}

\author{
Abi Prasidi ${ }^{1,}$ Muhamad. Rifni ${ }^{2}$ \\ ${ }^{1,2}$ Institut Transportasi dan Logistik Trisakti \\ prasidi393@gmail.com¹ ${ }^{1}$,rifnim@gmail.com²
}

\section{ARTICLE INFO}

\section{Article History}

Received : 30 October 2019

Reviewed: 10 February 2020

Published : 30 April 2020

Available Online: 30 April

2020

Keywords:

infrastructure capacity, government role, freight train

\begin{abstract}
Very limited capacity of the highway in some economies tract, such as the Trans Java traffic, has an impact on increasing the travel time especially in the use of rail transport, so that a certain pathway requires capacity building and the development of new lines gradually. The purpose of this research was to determine the capacity of rail transport infrastructure that is optimal for the distribution of goods, especially as the company managed by PT. Railway Logistics or KALOG. Another problem is how the government's role and the flow of freight transport demand. In the discussion, through a variety of existing data, the authors use research with phenomenological approach on the basis of qualitative analysis methods interpretative paradigm. Results are expected to be useful for improving knowledge about the needs of rail freight transport on goods distribution on the Java Island. The results of this research will be published in scientific journals. The purpose of this research are two folds. This research combination between qualitative data and quantitative data. The first is to calculate the technology contribution coefficient (TCC) and the second is to determine the priority of technology component development. This research has been done in PT. KALOG, a rail freight transportation company. To calculate the TCC, the author has used the technometric model and the analytical bierarchy process method. By improving these two components, operational problems will be minimized so that operating performance and sales volume will increase. It can then be expected that PT. KALOG will improve its rule in business competition.
\end{abstract}

\section{A. PENDAHULUAN}

Sebagai salah satu upaya menjamin kemudahan dalam sistem distribusi komoditas. Tersedianya jaringan prasarana KA dapat mendukung sistem logistik nasional, serta angkutan penumpang massal perkotaan dan antarkota. Potensi transportasi perkeretaapian tersedianya pada prasarana kereta api (panjang jalan kereta api) 4.861,10 m dan sarana kereta api berupa lokomotif 486 unit, KRD/KRL 920 unit, kereta 1.716 unit, serta gerbong 6.249 unit. Sementara, potensi pasar angkutan kereta api sangatlah besar ---khususnya terkait keunggulan kereta api dibandingkan moda lain, seperti kapasitas angkut, ketepatan waktu, dan biaya angkut yang lebih murah. Angkutan kereta api mendukung pengembangan multimoda yang terintegrasi dengan pengembangan transportasi umum lainnya ---khususnya pada kawasan perkotaan dan antarkota, baik pelabuhan, bandar udara, serta terminal-terminal bus AKDP/AKAP, angkutan feeder, dan bus rapid transit (rencana strategis kemenhub 2014-2019).

Menurut LPI (dalam Yunani, 2014), di Indonesia pengurusan pabean, infrastruktur, dan pengiriman barang internasional merupakan komponen terendah. Infrastruktur jalan, pelabuhan, dan bandara Indonesia masih buruk, selalu di bawah Thailand. Hanya infrastruktur kereta api jauh lebih baik, berada di urutan ketiga setelah Singapura dan Malaysia. Kelancaran pasokan dan distribusi di sektor riil merupakan salah satu pengendali inflasi. Ketidakefisienan distribusi tersebut akibat buruknya infrastruktur dan sistem logistik, sehingga akan menaikan harga barang di konsumen akhir. Dalam hal ini, pemerintah perlu mempercepat perbaikan jalan dan jembatan, sedangkan jangka panjangnya mempercepat pembangunan Pusat Distribusi Regional sebagai penyangga cadangan pangan nasional dan Pusat Disribusi Provinsi sebagai penyangga pangan provinsi, kabupaten, dan kota. Di samping itu, perlu segera tindak lanjut Perpres Nomor 26/2012 tentang Cetak Biru Pengembangan Sislognas, serta percepatan integrasi antarmoda (Kereta Api, trucking, 
transportasi laut). Bila mengingat kecelakaan bus pada peristiwa Comal, yang berdampak pada kenaikan permintaan layanan angkutan barang dengan kereta api. Namun, kenaikan ini tentu saja tidak bisa seluruhnya dipenuhi, sehingga pada akhirnya juga berdampak pada kualitas pelayanan kereta api. Untuk pengiriman volume besar dan jarak jauh, kereta api lebih efisien (cost per unit lebih rendah, no non-value added cost) dan ramah lingkungan. Angkutan petikemas dengan moda kereta api sebagai industri yang dapat dimanfaatkan sebagai distribusi barang dan logistik pelabuhan ke pelabuhan besar di Pulau Jawa dan Sumatera dengan melihat jalur kereta api yang sudah ada. Potensi kawasan industri yang banyak berada di sekitar Bekasi, Karawang, diharapkan penggunaan moda kereta api akan berdampak pada waktu tempuh yang lebih pendek, dan biaya yang lebih murah. Oleh karena itu, yang harus ditingkatkan adalah penyediaan sarana gerbong kereta api atau usaha kerja sama industri logistik dengan perusahaan kereta api. Untuk mengkaji permasalahan di atas, maka akan diuraikan lebih detail bagaimana keterbatasan infrastruktur, peranan pemerintah dalam regulasi optimalisasi infrastruktur, dan aliran permintaan angkutan barang. Sementara itu, fokus tulisan ini yaitu optimalisasi kapasitas infrastruktur angkutan kereta api terhadap distribusi barang pada PT. Kereta Api Logistik ---khususnya terkait dengan kapasitas infrastruktur, kondisi infrastuktur yang belum optimal, peran atau campur tangan Pemerintah dalam regulasi optimalisasi infrastruktur, angkutan kereta api logistik kalah bersaing dengan moda transportasi darat lain.

Pemilihan moda merupakan salah satu model terpenting dalam perencanaan transportasi karena peran kuncinya dalam angkutan umum. Moda angkutan umum menggunakan ruang jalan jauh lebih efisien dibandingkan dengan amgkutan pribadi. Moda kereta api memerlukan ruang jalan tersendiri, sehingga tidak menimbulkan kemacetan lalu lintas (Adisasmita, 2011). Menurut Nasution (2010), memilih moda transportasi untuk semua jenis produk tertentu, lazimnya pengirim mempertimbangkan tujuh kriteria, yaitu 1) kecepatan waktu pengantaran, 2) frekuensi pengiriman terjadwal, 3) kendala dalam memenuhi jadwal pada waktunya, 4) kemampuan menangani angkutan dari berbagai barang, 4) banyaknya tempat singgah atau bongkar muat, 5) biaya per ton-kilometer dan 6) jaminan atas kerusakan atau kehilangan. Menurut Tamin (2000), faktor yang mempengaruhi pemilihan moda, antara lain 1) ciri pengguna jalan, 2) ciri pergerakan dan 3) ciri kapasitas moda transportasi.

Jordan \& Thomson (1984) melakukan penelitian tentang lalu lintas kereta api dengan menelaah hubungan yang positif antara struktur ekonomi dan lalu lintas kereta api. Di sisi lain Rodrigue \& Comtois (2006) melakukan penelitian tentang korelasi yang kuat antara biaya transportasi dan jarak perjalanan untuk berbagai jenis moda transportasi (jalan kereta api,dan kapal laut) dalam angkutan barang. Secara generik moda transportasi jalan dengan kompetitif pada jarak pendek. Moda transportasi kereta api unggul pada jarak menengah, dan moda transportasi laut akan dominan pada jarak jauh. Maka dengan demikian kesimpulannya ada bila infrastruktur kereta api baik, otomatis pendistribusian barang dan logistik juga lebih tepat waktu dan kondisinya tetap baik di tempat tujuan distribusi.

Penelitian Xue Mei Lan, dkk (2016) yang mlakukan penelitian di Republik Guinea Afrika Barat menyimpulkan bahwa kontribusi infrastuktur terhadap kekuatan ekonomi, topik terkait infrastuktur menjadi topik yang menarik bagi akadmisi dan pembuat kebijakan. Temuan menunjukan bahwa infrastruktur memiliki hubungan positif terhadap pertumbuhan jangka panjang ekonomi dan lebih khusus lagi, konsumen listrik memiliki dampak signifikan pada pertumbuhan ekonomi di Republik Guinea. Penulis menyarankan agar Republik Guinea harus berinvestasi secara bijak di bidang infrastruktur. Maka kesimpulan ini infrastruktur tersebut bisa juga di kembangkan di Indonesia untuk mndukung transportasi kereta api agar pendistribusian barang dan logistik bisa sampai tepat waktu dan dengan demikian harga-harga logistik juga terjangkau oleh seluruh lapisan masyarakat.

Menurut Rodrigue (2013) adanya peningkatan perekonomian menunjukan bahwa investasi infrastuktur merupakan strategi yang tepat dalam menstimulasi perekonomian dan meningkatkan pendapatan seluruh golongan rumh tangga, melalui peningkatan ekonomi. Dari kesimpulan ini maka juga harga-harga pada kebutuhan rumah tangga suatu negara bisa terjangkau oleh seluruh lapisan masyarakat karena pembangunan infrastuktur yang dapat pendistribusian barang logistik kebutuhan rumah tangga suatu negara tepat waktu juga sampai kepada masyarakat yang membutuhkan.

\section{B. METODE PENELITIAN}

Penelitian fenomenologi termasuk pada paradigma interpretatif. Data yang diperoleh dengan in -depth interview dapat dianalisis. Dalam hal ini proses analisis data dengan Interpretative Phenomenological Analysis (IPA). Analisis Fenomenologis Interpretatif (IPA) adalah pendekatan penelitian kualitatif psikologi 
dengan fokus idiographic, yang bertujuan untuk menawarkan wawasan ke dalam bagaimana seseorang diberikan, dalam konteks tertentu, masuk akal dari fenomena tertentu (Smith, 2009). Dalam penelitian fenomenologi melibatkan pengujian yang teliti dan seksama pada kesadaran pengalaman manusia. Konsep utama dalam fenomenologi adalah makna. Makna merupakan isi penting yang muncul dari pengalaman kesadaran manusia. Untuk mengidentifikasi kualitas yang essensial dari pengalaman kesadaran dilakukan dengan mendalam dan teliti (Smith, 2009).

Berdasarkan wawancara yang mendalam (In-depth interview), permasalahan mengenai tantangan dalam meraih pangsa pasar pelayanan angkutan barang peralatan bongkar muat adalah pada kondisi infrastuktur yang belum optimal. Dari hasil wawancara berikut juga dicatat bahwa infrastruktur tersebut masih belum dilengkapi dengan sarana logistik, gudang barang, forklift, dan handlift. Upaya pengembangan moda transportasi kereta api untuk pengangkutan barang di Indonesia perlu diimbangi dengan pembangunan infrastruktur pendukung yang memadai, seperti terminal dengan fasilitas atau peralatan bongkar muat. Selain itu, operasionalisasi kereta api untuk pengangkutan barang harus dilakukan secara profesional ---dalam hal ini bisa dilakukan melalui kerja sama operasi dengan pihak swasta. Para pelaku usaha lebih memilih penggunaan truk daripada kereta api karena alasan handling, jadwal, aksesibilitas, dan sebagainya. Pengurangan beban jalan dapat dialihkan dan diseimbangkan dengan moda transportasi lainnya, seperti kereta api dan transportasi laut yang memiliki kapasitas daya angkut lebih besar dan waktu perjalanan yang relatif cepat, bebas pungutan liar dan keamanan serta keselamatan barang lebih terjaga. Faktor lain adalah lead time yang kurang lebih sama dengan truk dan harga total pelayanan yang kurang lebih sama juga, jika semuanya sama yang dikuatirkan adalah orang enggan berpindah ke moda transportasi kereta api walaupun nanti menggunakan jalur ganda. Sebagai gambaran lead time untuk truk ke Jakarta - Surabaya adalah 3 hari door to door (menggunakan truk yang sama) lead time untuk kereta api juga 3 hari.

KALOG yang fokus dan penguatan yang diwujudkan pada tahapan Pre-Service dan Post-Service dari layanan oleh PT Kereta Api Indonesia (Persero) serta integrated-service berbasis information technology sepanjang rantai jasa layanan distribusi logistik. Dalam semua kegiatan tersebut di atas sangat diperlukan alat penunjang forklift hidrolik dan Penjepit Muatan agar pencapaian lead time terukur dan meningkatkan pelayanan integrated service.

\section{HASIL DAN PEMBAHASAN}

Penelitian ini menggunakan penggabungan data kualitatif dan kuantitatif. Data kualitatif digunakan untuk mengidentifikasi nilai tingkat kecanggihan teknologi dan nilai state of the art pada 4 (empat) komponen teknologi THIO. Penggunaan data kuantitatif dilakukan untuk mendapatkan nilai kontribusi komponen teknologi dengan menggunakan persamaan model teknometrik Sumber data yang digunakan dalam penelitian ini adalah data primer dan data sekunder. Data primer adalah data yang dikumpulkan dan diolah sendiri oleh peneliti yang diperoleh melalui pengamatan langsung dari wawancara responden di divisi angkutan container. Sedangkan data sekunder diperoleh dari dokumen internal PT. KALOG dan literature lainnya seperti buku, jurnal, laporan hasil penelitian, kebijakan pemerintah yang terkait dengan transportasi dan teknologi transportasi. Lokasi penelitian dipilih secara pitposive berdasarkan hasil diskusi dengan PT. KALOG yaitu area operasi angkutan kontainer di Terminal Barang Sungai Lagoa Tanjung Priok. Pengumpulan data dilaksanakan pada bulan Oktober 2017. Penggalian informasi dilakukan melalui pengamatan langsung, wawancara dan diskusi. Responden pada penelitian terdiri atas 12 (dua belas) orang pegawai yang terlibat dalam proses operasi angkutan kontainer yaitu staf pelaksana, supervisor, manajer serta vice president. Sedangkan responden pakar yang memberikan penilaian intensitas kontribusi komponen teknologi adalah 5 (lima orang) manajer yang memiliki pengalaman dibidang pengelolaan komponen teknologi.

Keterbatasan infrastruktur

Salah satu permasalahan yang cukup penting adalah Infrastruktur yang belum dilengkapi dengan sarana logistik, seperti gudang barang, forklift, handlift. Dalam hal ini, berdasarkan wawancara yang mendalam (In-depth interview), permasalahan mengenai tantangan dalam meraih pangsa pasar pelayanan angkutan barang peralatan bongkar muat adalah pada kondisi infrastuktur yang belum optimal. Dari hasil wawancara berikut juga dicatat bahwa infrastruktur tersebut masih belum dilengkapi dengan sarana logistik, gudang barang, forklift, dan handlift. Upaya pengembangan moda transportasi kereta api untuk pengangkutan barang di Indonesia perlu diimbangi dengan pembangunan infrastruktur pendukung yang memadai, seperti terminal dengan fasilitas atau peralatan bongkar muat. Selain itu, operasionalisasi kereta api untuk pengangkutan 
barang harus dilakukan secara profesional dalam hal ini bisa dilakukan melalui kerja sama operasi dengan pihak swasta. Angkutan barang (logistik) di Indonesia masih didominasi oleh angkutan jalan. Kondisi tersebut mengakibatkan sering terjadi kecelakaan lalu lintas dan meningkatnya kerusakan jalan. Selain itu, terlalu banyaknya angkutan barang melalui transportasi jalan tidak hanya menimbulkan kerugian ekonomi, tetapi juga tidak ramah lingkungan akibat kemacetan dan yang dapat meningkatkan emisi gas buang. Para pelaku usaha lebih memilih penggunaan truk daripada kereta api karena alasan handling, jadwal, aksesibilitas, dan sebagainya. Pengurangan beban jalan dapat dialihkan dan diseimbangkan dengan moda transportasi lainnya, seperti kereta api dan transportasi laut yang memiliki kapasitas daya angkut lebih besar dan waktu perjalanan yang relatif cepat, bebas pungutan liar dan keamanan serta keselamatan barang lebih terjaga. Faktor lain adalah lead time yang kurang lebih sama dengan truk dan harga total pelayanan yang kurang lebih sama juga, jika semuanya sama yang dikuatirkan adalah orang enggan berpindah ke moda transportasi kereta api walaupun nanti menggunakan jalur ganda. Sebagai gambaran lead time untuk truk ke Jakarta - Surabaya adalah 3 hari door to door (menggunakan truk yang sama) lead time untuk kereta api juga 3 hari. Ambil barang dari pelanggan menggunakan truk 1 hari, perjalanan kereta 1 hari, kirim ke customer juga 1 hari. Jika kelebihan beban per dari kereta api ini juga bisa patah, maka lead time juga akan membengkak sama halnya dengan truk. Secara khusus penggunaan kereta api sebagai moda pengangkutan barang tidak akan merugikan perusahaan-perusahaan transportasi jalan (trucking), tetapi justru akan meningkatkan produktivitas transporter tersebut. Kemacetan jalan berakibat produktivitas (jumlah trip) truk sangat rendah. Penggunaan kereta api akan bisa mengurangi beban dan kemacetan di jalan.

KALOG sebagai perusahaan angkutan kereta api logistik yang berorientasi bisnis sebagai penyedia jasa layanan distribusi logistik secara total (Total Logistics Solution) melalui "End-to-End Services" atau dengan kata lain sebagai SCM Service Provider. KALOG juga sebagai " pencipta nilai tambah (value-added creator) sepanjang rantai nilai (value chain) layanan distribusi logistik, termasuk layanan yang telah disediakan oleh PT. Kereta Api Indonesia (Persero), seperti angkutan barang dan gudang. KALOG yang fokus dan penguatan yang diwujudkan pada tahapan Pre-Service dan Post-Service dari layanan oleh PT Kereta Api Indonesia (Persero) serta integrated-service berbasis information technology sepanjang rantai jasa layanan distribusi logistik. Dalam semua kegiatan tersebut di atas sangat diperlukan alat penunjang forklift hidrolik dan Penjepit Muatan agar pencapaian lead time terukur dan meningkatkan pelayanan integrated service.

\section{Peran Pemerintah}

Melihat begitu banyaknya perencanaan pada RPJMN 2015-2109, Strategi dan Arah Kebijakan Ditjen Perkeretaapian 2015-2019, Rencana Induk Perkeretaapian Nasional (RIPNas) tahun 2011, cukup banyak yang tidak dapat direalisasikan. Hal ini tercatat juga dalam wawancara yang mendalam (in-depth interview), bagaimana peran pemerintah dalam mendorong atau mempercepat kegiatan kereta api logistik berjalan dan membantu masalah transportasi barang, ternyata jika melihat realisasinya bahwa tidak ada peran atau campur tangan pemerintah dalam regulasi optimalisasi infrastruktur. Dapat dilihat banyak detail rencana pada angkutan kereta api logistik sebagai berikut.

\section{Program Pemerintah}

Beberapa rencana program pemerintah yang akan dilaksanakan, yaitu

a) kebutuhan Pengembangan Sislognas (Pokok-pokok arahan Menko Perekonomian RI, 2015): Peningkatan Peran Kereta Api Kargo di Jawa dan Sumatera, dan

b) target Perkeretaapian dalam RPJMN 2015-2019, yaitu.

1) Jumlah barang yang diangkut KA menjadi 1,5 juta TEUs/Tahun, dan

2) Pangsa muatan angkutan KA minimal 5\% (barang).

Sementara itu, pangsa pasar kereta api saat ini masih relatif rendah. Dalam hal ini, barang baru mencapai $0,6 \%$ dari angkutan barang secara nasional pada 2010 jumlah total, sedangkan angkutan barang sebesar 19.149.000 ton.

3) Peningkatan kapasitas jalur eksisting menjadi jalur ganda di pulau Jawa.

c) Strategi dan Arah Kebijakan Ditjen Perkeretaapian 2015-2019, yaitu aspek kebijakan Pembangunan Perkertaapian melalui pengembangan jaringan pelayanan yaitu, integrasi layanan dengan moda lainnya dan meningkatkan aksesibilitas masyarakat kerhadap layanan KA.

2. Pengembangan Jaringan Jalur Kereta Api

Sasaran pengembangan jaringan jalur kereta api di pulau Jawa adalah mengoptimalkan jaringan eksisting 
melalui program peningkatan, rehabilitasi, reaktivasi lintas non operasi serta peningkatan kapasitas lintas melalui pembangunan jalur ganda dan shortcut. Pembangunan jalur KA pelabuhan lintas Karawang Cilamaya. Tanjung Perak, Tanjung Emas, Ujung Jabung, Patimban, Tanjung Intan, Panarukan. Upaya pengembangan moda transportasi kereta api untuk pengangkutan barang di Indonesia perlu dibarengi dengan pembangunan infrastruktur serta sarana prasarana pendukung yang lebih memadai, seperti terminal dengan fasilitas/peralatan bongkar muat. Selain itu, operasionalisasi kereta api untuk pengangkutan barang dan logistik harus secara profesional, yang bisa dilakukan melalui kerja sama operasi dengan pihak swasta.

Permintaan terhadap Pengangkutan Barang dan Logistik

Menurut studi Joris Van der Ven atas potensi pasar kereta api di Indonesia pada 2009, penyebab masalah tersebut bisa disebabkan beberapa faktor, antara lain kebutuhan transportasi dalam perekonomian yang tidak statis, makin selektifnya dunia usaha dan orang-orang yang melakukan perjalanan dalam memilih moda transportasi, serta kurangnya dukungan dan perhatian dari pemerintah terhadap pengembangan infrastruktur kereta api khususnya untuk mendukung industri dalam negeri. Dalam hal ini, kelemahan tersebut terletak pada penggunaan rel kereta api jalur ganda terhadap logistik. Dalam wawancara mengenai kondisi layanan Angkutan Kontainer Kereta Api yang sebenarnya memiliki sejumlah keunggulan, tetapi tidak dilirik oleh Industri barang dan jasa, tercatat juga bahwa aliran permintaan angkutan barang dari barat ke timur dan sebaliknya di pulau Jawa tidak terdistribusi secara merata. Rencana kereta api logistik dalam pelayanan sudah terlihat yaitu secara progress sudah ada peningkatan pra dan purna angkutan untuk door-to-door service dengan adanya kolaborasi dengan pihak ketiga. Terobosan produk sudah dilakukan agar para pengusaha atau Industri mau menggunakan jasa kereta api logistik dimana peluang sangat terbuka dengan adanya kolaborasi dengan kawasan industri, penguasa logistik, dan penerbangan misalnya Garuda Cargo. Dari segi pelayanan sarana dan prasarana sudah terlihat peningkatan pada Kawasan Pergudangan Terpadu Kampung Bandan, Jakarta. Sementara itu, Biaya logistik menjadi sangat tinggi karena belum efektifnya sistem dan mata rantai logistik Penambahan rel ganda pada dasarnya tidak berdampak besar terhadap logistik jika tidak diikuti dengan kesiapan bongkar muat di stasiun. Persoalannya tidak hanya di stasiun, tetapi juga perjalanan dari stasiun ke gudang. Layanan kereta api ini agak menyulitkan logistik karena layanannya tidak dari pintu ke pintu (door to door), sehingga biayanya juga tidak turun. Sebagai contoh, biaya logistik dengan truk Jakarta-Surabaya sebesar Rp 4 juta-Rp 5 juta dengan waktu tempuh tiga hari. Sementara dengan kereta api sekitar Rp 2,5 juta dan waktu hanya satu hari. Namun, waktu bongkar muat bisa dua hari, sementara biaya dari stasiun ke gudang bisa Rp 1,5 juta. Maka jika infrastruktur di stasiun kereta api belum ada, dan letak gudangnya jauh, upaya pemasangan jalur ganda ini tidak maksimal. Pangsa muatan angkutan KA minimal 5\% (barang). Dengan demikian, maka wajarlah jika pangsa pasar kereta api saat ini masih relatif rendah. Dari hasil wawancara mengenai produk layanan kereta api logistik mengapa tidak sepopuler produk layanan alat transport yang lain ---seperti pesawat udara atau kapal laut juga mengenai infrastruktur dan layanan kurang menarik bagi para pelanggan seperti agen logistik, Usaha kereta api logistik untuk melakukan usaha kegiatan pelayanan angkutan dengan pembagian dari empat produksi layanan seperti, Semen (50\%), Batu bara 20\%, Container 30\% dan BHP (10\%)Produk layanan jasa forwarding hingga saat ini masih mengutamakan FCL (full container load) namun kedepannya juga tidak menutup kemungkinan membuka layanan LCL (less than a container load). Selain itu, perlu dikembangkan juga Area Pergudangan Transit, yaitu suatu menggunakan rangkaian kereta api.

\section{D, KESIMPULAN}

Fokus dan penguatan peran penting PT. KALOG dapat diwujudkan pada tahapan Pre-Service dan Post-Service serta integrated-service berbasis information technology sepanjang rantai jasa layanan distribusi logistik. Melihat Rencana Induk Perkeretaapian Nasional (RIPNas) 2011 ternyata pada saat ini, simpul-simpul transportasi dan logistik di pulau Jawa-Bali seperti bandara, pelabuhan, dryport dan pusat-pusat produksi (industri dan manufaktur) belum dihubungkan dengan jaringan kereta api, terutama untuk mengatasi peningkatan beban pengangkutan barang di jalan raya. Infrastruktur di stasiun kereta api belum ada, dan letak gudangnya cukup jauh, upaya pemasangan jalur ganda ini juga tidak maksimal. Dengan tingginya biaya transportasi dan rumitnya mata rantai distribusi sering memicu gejolak harga pangan dan inflasi. Biaya logistik menjadi sangat tinggi karena belum efektifnya sistem dan mata rantai logistik. Adanyanya tersedianya dana untuk membangun infrastruktur yang dicanangkan oleh Pemerintah dan dukungan Pemerintah juga sinergi melalui dukungan pihak swasta melalui proyek pembangunan rel-rel kereta api dengan open manajemen dan adil agar distribusi barang berupa logistik sampai ke tempat tujuan secara tepat waktu yaitu dibangunnya infrastruktur rel yang lebih efisien dan efektif. 


\section{DAFTAR PUSTAKA}

[1]. Adisasmita, Sakti Adji, 2011. Jaringan Tra nsportasi: Teori dan Analisis. Yogyakarta: Graha Ilmu.

[2]. Afrizal. Metode Penelitian Kualitatif: Sebuah Upaya Mendukung Penggunaan Kualitatif dalam Berbagai Disiplin Ilmu. Jakarta, 2014 : RajaGrafindo Persada.

[3]. Barus, Lita Sari, Sigit Pranowo Hadiwardoyo, Hipolito Martell-Flores \& Jean-Louis Batoz. 2013. Modal Competition for Freight in Land Transportation on Jakarta-Surabaya corridor. Civil and Environmental Research www.iiste.org Vol.3 (11).

[4]. Forkenbrock, David J. 1998. External Costs of Trucks and Rail Freight Transportation. Public Policy Cente Public Policy Center The University of Iowa.

[5]. Hamidi. 2004. Metode Penelitian Kualitatif: Aplikasi Praktis Pembuatan Proposal dan Laporan Penelitian. Malang: UMM Press.

[6]. [Kemenhub RI] Kementerian Perhubungan. 2011. Rencana Induk Perkeretaapian Nasional. Direktorat Jenderal Perkeretaapian. Jakarta: Kemenhub RI.

[7]. [Kemenhub RI] Kementerian Perhubungan. 2015. Progres Kegiatan Evaluasi Kemanfaatan Kegiatan Pembangunan Sektor Transportasi Di Lingkungan Kementerian Perhubungan Tahun Anggaran 2015. Jakarta: Kemenhub RI.

[8]. [Kemenhub RI] Kementerian Perhubungan. 2015. Peta Lokasi Kegiatan Strategis Pembangunan Transportasi Dalam Rencana Strategis Kementerian Perhubungan Tahun 2015-2019. Jakarta: Kemenhub RI.

[9]. [Kemenhub RI] Kementerian Perhubungan. 2015. Rencana Strategis Pembangunan Perkeretaapian Tahun 2015-2019, Direktorat Jenderal Perkeretaapian. Diskusi Terbatas Prospek Investasi Infrastruktur 2015-2020. Jakarta: Kemenhub RI.

[10]. Kereta Api Logistik. 2013. True Power To Be A Leader. Annual Report. 2013.

[11]. Lemhanas. Pengembangan Sistem Transportasi Nasional guna Mempercepat dan Memperluas Pembangunan Ekonomi dalam Rangka Ketahanan Nasional. Jurnal Kajian Lemhannas RI. Edisi 15. Mei 2013.

[12]. Menko Perekonomian RI]. Menteri Perekonomian. 2015. "Kebutuhan perlunya Pengembangan Sislognas". Pokok-pokok arahan Menko Perekonomian RI, 2015. Business Forum Strategi Pengembangan Industri Jasa Logistik Nasional.

[13]. Nasution, M. Nur. 2010. Manajemen Transportasi. Edisi ke tiga. Jakarta: Ghalia Indonesia.

[14]. [Perpres RI] Peraturan Presiden. 2012. Peraturan Presiden Republik Indonesia Nomor 26/2012 Tentang Cetak Biru Pengembangan Sislognas. Jakarta: Perpres RI.

[15]. Prasetyo, Ardyah Eko \& Firmanto Hadi. 2013. Analisis Pemindahan Moda Angkutan Barang di Jalan Raya Pantura Pulau Jawa (Studi kasus: Koridor Surabaya - Jakarta). Jurnal Teknik Pomits Vol. 2 (1).

[16]. Ridwan, Mohd. 2011. Studi Komparatif Angkutan Barang Menggunakan Moda Laut Dan Darat Di Pulau Jawa. Jurnal Teknik - Vol. 32 (3). Tahun 2011, ISSN 0852-1697.

[17]. Simatupang, Togar M. 2015. Pelabuhan Bukan Akar Masalah. Majalah Transportasi Indonesia. Edisi 12. 25 April-25 Mei, 2015.

[18]. Smith, Jonathan A., Paul Flowers \& Michael Larkin. 2009. Interpretative phenomenological analysis: 
Theory, method and research. Los Angeles, London, New Delhi, Singapore, Washington: Sage.

[19]. Tamin, Ohyar Z. 2003. Transportation Planning and Modelling: Perencanaan dan Permodelan Transportasi: Problem and Aplication. ITB Press, Bandung : Indonesia.

[20]. Woroniuk, Clare, Paulus Aditjandra \& Thomas H Zunder. 2014. An investigation into rail freight capacity in Indonesia. NewRail, Newcastle Centre for Railway Research, Freight \& Logistics Research Group, School of Mechanical and Systems Engineering, Newcastle University, Newcastle upon-Tyne, NE1 7RU, United Kingdom.

[21]. Yunani, Ahmad. 2014. Pengangkutan Barang Dengan Truk Atau Kereta Api. Seminar Aston Primera Pasteur, Bandung. 